\title{
OTR1 - AVALIAÇÃO DE UM SISTEMA DE INFORMAÇÃO ONLINE PARA GERENCIAMENTO DE ESTUDOS CLÍNICOS
}

$\underline{\text { Maria de Lourdes de Sousa Maia }}{ }^{1}$, Vanessa dos Reis von Doellinger ${ }^{1}$, Paulo Roberto Gomes dos Santos ${ }^{1}$, Suelen Renata Estácio Marques ${ }^{1}$, Elizabeth Maciel de Albuquerque ${ }^{1}$, Luiz Antonio Bastos Camacho ${ }^{2}$, Marilia Santini ${ }^{3}$.

1 - Bio-Manguinhos / Fiocruz

2- Escola Nacional de Saúde Pública/Fiocruz

3- Instituto de Pesquisa Clínica Evandro Chagas/Fiocruz

\section{OBJETIVO}

Avaliar o desempenho de um sistema de informação online para gerenciamento de estudos clínicos (Geclin).

METODOLOGIA: O Geclin foi avaliado durante a condução de três estudos clínicos: um de Fase II com a vacina meningocócica C (conjugada), um de Fase II/III com a vacina meningocócica B (polissacarídica) e outro de Fase IV com a vacina sarampo, caxumba e rubéola, realizados na unidade de ensaio clínico da Assessoria Clínica de BioManguinhos/Fiocruz e em centros municipais de saúde do Rio de Janeiro, em 2012 e 2013.

RESULTADOS: Após a introdução do Geclin, verificaram-se melhorias na transmissão e segurança da informação junto ao patrocinador. $\mathrm{O}$ acesso online ao sistema permitiu armazenar e atualizar dados em tempo real e com proteção de confidencialidade sobre os sujeitos de pesquisa e o cronograma de acompanhamento de atividades relacionadas aos estudos clínicos. Com o ambiente virtual, pode-se observar a agilidade no andamento do estudo, identificando e interagindo com os profissionais de pesquisa, nos centros colaboradores e na unidade da Asclin, para corrigir problemas em tempo oportuno, reduzindo gastos com infraestrutura, materiais, horas-homem e horas-carro.

Com a implementação do sistema, o tempo mínimo para disponibilizar as informações para tomada de decisões caiu de uma semana para o momento em que a informação era registrada no sistema, ou seja, em tempo real. Desta forma, o tempo de trabalho de campo pôde ser reduzido à metade e o tempo para monitoria a um terço, aproximadamente. 


\section{CONCLUSÃO}

O Geclin se mostrou um instrumento valioso para acompanhamento do trabalho de campo em pesquisa clínica, permitindo avaliar cenários e detectar necessidades de ajustes durante o desenvolvimento dos estudos, dando aos gestores a possibilidade de tomada de decisão em tempo oportuno. Verificou-se que o sistema atende ao objetivo de apoiar as atividades relacionadas à gestão de pesquisa clínica, tais como: planejamento, recrutamento de sujeitos de pesquisa, desenvolvimento de trabalho de campo, gerenciamento de dados para tomada de decisão e elaboração de relatórios, tornando possível o acompanhamento de vários estudos clínicos, ao mesmo tempo e em locais diferentes, de acordo com as Boas Práticas Clínicas estabelecidas pelo Documento das Américas e exigidas pela Anvisa. 